\title{
Mort, Identité, Langue dans l'oeuvre de Mohammed Kheir-Eddine
}

\author{
Tassadit Yacine \\ CNRS
}

Tu dois aimer la montagne; tu es ta montagne, un grain de ta montagne. (Légende et vie d'Agounchich)

Q uel lien peut-on établir entre anthropologie et écriture, mémoire et histoire ou, peut-être encore, entre mort et identité ? Pourquoi la problématique de l'identité telle que la pose le roman est souvent la traduction d'une vision souvent atroce de la mort?

La lecture du roman de Mohammed Kheir-Eddine ne peut être comprise que si elle est replacée dans un cadre, celui de "littérature mineure" pour reprendre le concept de Deleuze et Guattari. Création dans un espace où la langue n'existe pas pour elle-même, où la culture gît encore dans l'indétermination, l'indéfinissable.

Légende et vie d'Agounchich nous situe d'emblée devant un complexe, celui de la langue mineure, de l'identité refoulée et de la littérature mineure. ${ }^{1}$

Vers quelle lecture nous mène Légende et vie d'Agounchich? Vers la réalité, la vie, le récit, la biographie, la fiction. Réalité et fiction ou réel jeté dans la fiction comme celui du héros, Agounchich, (du chleuh: tronc d'arbre) situé dans la présence-absence, dans la nonvie ou dans la non-mort. Ensemble antithétique dans lequel se débat le protagoniste.

La lecture que l'on peut faire de l'œuvre aujourd'hui n'est éclairante que si on essaie de la rapprocher de ceux qui ont adopté des conduites analogues : Mouloud Mammeri, Mouloud Féraoun, Malek Ouary ont en effet rapporté des récits similaires où la légende et la réalité se confondent. La mort et l'esprit de vengeance occupent l'œuvre. La Terre et le Sang $^{2}$ de Mouloud Féraoun montre les liens inextricables entre la terre natale et la reproduction qu'elle soit biologique ou culturelle.

Les effets de la colonisation et de la Seconde Guerre mondiale seront déterminants sur les paysans de Kabylie. Pour survivre, la population déplace le drame.

La tribu va sécréter des éléments pour s'auto-détruire, se détruire de l'intérieur. C'est le 
jeune Amer, fraîchement arrivé de Kabylie, qui va tuer à son insu son oncle et protecteur Rabah dans les mines du Nord. Amer n'a été qu'un instrument entre les mains d'André, le Polonais, qui tente de se débarrasser d'un rival. La mort accidentelle de Rabah sera à l'origine d'un drame qui va déterminer la vie de Amer qui, se sentant coupable, épousera Marie (la fille du meurtrier), qu'il ramènera vivre au village. Mais l'amour de Amer pour Marie obéit au règlement d'une dette, il ne peut donc pas être amour véritable. Le véritable amour c'est celui qui transgresse, qui bouscule, qui donne la vie au prix de la mort. Les amours interdites de Amer et de Chabha conduiront vers leur fin Amer et Slimane (le mari de Chabha). La terre a lavé son honneur du sang de ceux qui ont violé la loi. Le viol de la loi (de la femme) n'est qu'une forme de reconnaissance de cette même loi.

Mouloud Mammeri, dans le Sommeil du juste, ${ }^{3}$ nous conduit au cœur d'un drame familial où, comme dans les contes, deux frères, c'est-à-dire deux êtres en principe égaux par la naissance, sont pourtant socialement défavorisés de façon inégale. L'un est doté d'un capital économique important mais pauvre par ailleurs: il n'a qu'un héritier à qui transmettre l'héritage. A l'inverse, le frère cadet a une progéniture nombreuse mais ne dispose pas d'héritage à léguer. C'est sur ce partage inégal que le pauvre décide de venir à bout du pouvoir du riche en le privant de son unique héritier. Dans son agonie, le jeune homme recommande à son père de rendre son bien à l'oncle Abed. C'est ainsi que le frère aîné décime toute la famille, son propre frère et l'ensemble de ses descendants mâles jusqu'à l'enfant suçant le sein de sa mère. Le héros, héritier de la tradition, ne pouvait pas la trahir.

Il fallait se hâter de se libérer de cette tragédie qui broie la tribu et se lancer dans le monde moderne. Mais l'entrée dans le monde moderne est aussi meurtrier, il n'est pas symbole de mort mais de destruction. Arezki, le héros, brûle ses livres pour effacer le souvenir des lettres, de l'écrit qui l'ont effacé de l'histoire.

Malek Ouary part également d'un fait vécu, analogue aux précédents, pour retracer l'histoire collective d'un village. ${ }^{4}$ Mais le village n'est que le reflet de la nation en son entier. Deux groupes, deux clans, représentés ici par deux hommes : celui qui est lésé, qui a subi l'injustice, et celui qui a transgressé la loi du groupe en infligeant la honte et le mépris, synonymes de déshonneur, de mort sociale. Ces deux hommes représentant les deux faces de Janus vont se combattre jusqu'à la mort. Seules des épreuves relevant du rituel initiatique ancien pourront aider le candidat à la mort en acceptant sa propre mort. Il ne s'agit pas de se laisser abattre mais de se laisser mourir à son groupe, à sa famille, à son nom pour se revêtir du nom et du renom de la famille du « défunt ». Pour sceller l'alliance, le clan adverse lui demande de rentrer dans la famille, de mélanger le sang au sang, en épousant leur fille (la sœur du mort). Par cette formidable métaphore Ouary nous montre comment la roue imposante et destructrice broie les grains de l'olive. Seul celui qui s'incruste dans les rainures peut en réchapper sauf si et seulement s'il participe au broyage de tous ses semblables. La meule ayant ici une fonction double : la tradition «barbare » et meurtrière mais aussi la civilisation récente qui va broyer les êtres et leur culture et n'y échapperont que les indigènes qui s'incrusteront dans la toute-puissance au prix de la mort 
de tous les autres.

N'est-ce pas là la trajectoire de Jean Amrouche, qui, malgré sa culture française, malgré sa religion catholique, va se retrouver porte-parole de ceux qu'il appelle « les sourdsmuets ", (les Algériens, ses frères de désespoir) et militer par le biais de la langue de l'autre. L'Eternel Jugurtha publié en $1943^{5}$ constitue un texte fondateur qui va signer l'identité nord africaine. Jugurtha, l'ancêtre mythique défenseur de la tribu, se perd en perdant sa culture, sa langue.

La quête de Kateb Yacine, comme celle de Chraïbi, est sans doute la plus aiguë, la plus désespérée, car Kateb est conscient de la perte irrémédiable de la langue. Il en est lui-même un produit vivant, une victime de l'aliénation qui a affecté bien des peuples, dont le sien. Dans une préface aux poèmes chantés de Lounis Aït Menguellet, Kateb Yacine raconte comment il a réalisé l'importance de la langue et de l'identité en croyant que toute l'Algérie avait une seule et même langue: l'arabe. ${ }^{6}$

Moi-même, je le croyais, jusqu'au jour où je me suis perdu en Kabylie. Pour retrouver mon chemin, je me suis adressé à un paysan sur la route. Je lui ai parlé en arabe. Il m'a répondu en tamazight. Impossible de se comprendre. Ce dialogue de sourds m'a donné à réfléchir. Je me suis demandé si le paysan kabyle aurait dû parler arabe, ou si, au contraire, j'aurais dû parler tamazight - la première langue du pays depuis les temps préhistoriques.

Les envahisseurs étrangers n'ont cessé de la refouler. Il y a eu les siècles de domination romaine, arabo-islamique, turque, et enfin française. Tous ces envahisseurs ont voulu imposer leur langue, au détriment du tamazight.

Peut-on comprendre Kheir-Eddine sans essayer de revenir aux conditions culturelles et politiques qui ont habité les hommes et les femmes de cette génération? Sans entrer dans le texte lui-même (ce qui va constituer le corps du roman), le lecteur est frappé par le préambule. Kheir-Eddine, comme Féraoun, lie la réalité nue et crue à la fiction. C'est peutêtre le pré-texte (l'avant-texte, en réalité une mise en garde d'avant-garde) qui permet d'associer la légende et la vie d'Agounchich : l'apparent et l'occulte, la vie avec tout ce qui est visible et implicite. Le Sud, cette région tant appréciée, est aussi un habit, des couleurs,

l'habit des femmes: la tamelhaft, drap noir et ample au liséré rouge, et la tacheddat, bandeau également noir décoré d'un rang de bâtonnets de corail qui ceint la tête recouverte d'une large étoffe rouge. Comme on le voit, la femme chleuh qui vit toute l'année dans sa montagne est d'abord un être doublement coloré : un être extérieurement rouge et noir. Cependant la modernisation grignote peu à peu la beauté millénaire des choses; cela se remarque surtout à des détails infimes comme ces bâtonnets de corail remplacés depuis quelques années par des bâtonnets en matière plastique. Ou comme les fibules en argent et les lourds colliers d'ambre et de pièces de monnaie anciennes auxquels se substituent des 
épingles de nourrice et des cordonnets dont la femme attache son habit noir au niveau des seins. De tout temps, la femme berbère a été pourvoyeuse des significations cachées du monde. C'est elle qui inculquait aux très jeunes enfants la culture ancestrale que l'homme, trop paresseux quand il n'était pas occupé dans les mines d'Europe ou les épiceries de Casablanca, ne leur dispensait pas. ${ }^{7}$

Agounchich constitue un lien, il est l'acteur (celui qui joue des tours et déjoue les ruses), il est le héros mais un héros candidat à la mort. Il se retrouve donc porteur d'une mémoire, la mémoire vivante, la mémoire retraçant le passé mais le présent aussi.

Agounchich, le tronc (tronc d'arbre mort), se situe dans l'ambivalence ou la vie-mort, la non-vie puisqu'au nom de la mort il meurt à la vie du groupe. Il se réfugie dans la montagne (ou le désert : lexla des Kabyles), espace réservé aux animaux et aux esprits.

Agounchich refuse la société des hommes, sa justice pour se faire justice lui-même. Mais c'est dans cette retraite qu'il retrouve toute sa puissance d'homme et d'homme viril : celui qui n'a peur de rien, de personne, pas même des revenants, pas même des légendes fussent-elles celles de la jument des tombes, de Ahmed Ou Moussa ou encore du célèbre Hammou Ou Nammir qui terrorisent les hommes. C'est donc le plus vivant de tous les morts. Il représente ainsi la mémoire des morts, des morts innocents (sa propre sœur, son moi à la fois semblable et différent). Il est vivant mais de cette vie qui ne fait plus sens dans la société des humains.

Vie fictionnelle, vie animale (au sens où les animaux ne donnent la mort que pour survivre) célébrée de façon hyperbolique par le héros et le narrateur. Agounchich va donc se survivre (survivre à la pulsion de mort) en habitant la montagne, hantée par les esprits, hantée par la mauvaise conscience. Tout ce qui foule la justice et refoule la culture. Mais la fuite a une limite, la résistance a un terme. Le héros mort, c'est la civilisation représentée par la colonisation française qui va entrer avec la chute des derniers remparts de la résistance de la tribu berbère.

Les villages de montagne seront ainsi bombardés par l'arme moderne. Cette arme ignore le face-à-face, la confrontation (amqabel). L'arme qui ne reconnaît pas l'autre comme adversaire mais comme objet à détruire. Le Sud, écrit Kheir-Eddine, c'est d'abord une « langue ».

C'est en fait cette forme de mort qui est synonyme de mort, de fin, de terme. Mort destructrice, mort violente, mort négative qui condamne à mort la création et la re-création, le jeu. La conception de la mort dans Agounchich (et pour le héros) est synonyme de mortvie, de jeu, en ce qu'elle est ouverture sur la vie malgré la pulsion de mort.

Le candidat à la mort est vivant, il est omniprésent. Il faut le chercher, le traquer et lui donner la mort en respectant les règles du jeu, en observant la loi ancestrale, ses rites et ses mythes.

Le fait de tuer n'est rien tant que ça ne dérange pas l'ordonnancement de l'univers. Ce qui importe, ce qui prime tout le reste, y compris ton existence et la mienne, 
c'est l'accord qu'on passe ici ou là, de temps en temps, avec soi-même et avec les autres... Cette espèce d'harmonie fugitive qui vous condamne à vivre ou à périr. Je n'ai jamais déserté ma maison ! Ni tué mon amour pour la terre et pour les êtres. Cependant, je marche, je vais, je cours, je cherche sans relâche quelque chose qui me fasse désirer la vie.

Comme dans la tragédie antique Agounchich est suspendu aux rythmes du flux vital. Il en a conscience, il aspire la vie à grandes gorgées car il sait désormais que la culture des ancêtres se dissout dans le nouvel univers qui fait voler en éclat l'harmonie:

Cette culture ne se donnait pas comme un apprentissage au sens scolaire, mais comme un travail de patience et de méthode qui consiste à nourrir le cerveau de l'enfant de légendes symboliques tout en lui faisant connaître les beautés diverses et immédiates de la terre. Les changements de saison se transformaient en festivités dionysiaques où le désir vital acquérait une dimension propre aux mythologies les plus envoûtantes. La femme apparaissait alors comme une déesse bienveillante, car elle composait avec les éléments, elle était les éléments et tout ce qui les embellissait aux yeux des hommes ; mais c'est au printemps, lorsque les torrents frangés d'écume brune et duvetés de tamaris verts roulaient un tam-tam de galets assourdi, qu'elle s'épanouissait et devenait aussi aérienne qu'une antilope. Elle se confondait avec la renaissance de la Nature.'

La mort importée d'Occident (de l'ouest, de l'univers des ombres et de la pénombre) est froide, glaciale car au nom de la Civilisation (qui s'impose comme universelle) elle détruit tout, elle donne la mort de manière massive, sans discernement. Elle ignore l'identité du futur mort, ce dernier meurt dans un groupe compact qui représente le tout, qui incarne la civilisation des ancêtres, des vaincus pour toujours. Avec leur mort se meurent le nom, le renom, l'histoire et... du coup, la mémoire. Mémoire qui n'a plus de raison de se perpétuer car on a effacé les traces des ascendants en anéantissant les descendants. Alors à quoi bon?

Cette mort, sanction, punition globale et indifférenciée, est du coup sans création, sans jeu... Elle extermine de façon implacable et universelle. Tout le monde est égal devant la mort: hommes, femmes, enfants, animaux et plantes.

Comme les écrivains berbères de Kabylie, Kheir-Eddine décrit avec angoisse une civilisation vouée à l'extinction. Civilisation d'Afrique du Nord doublement menacée : de l'intérieur et de l'extérieur. La mort qui de l'intérieur la guette en dressant les fils du pays chleuh contre la montagne nourricière ; ces derniers la vident de sa substance, de son énergie en se faisant prolétaires dans les grandes villes. Ils deviennent des pions, des relais d'un système économique qui leur enlève jusqu'à leur propre âme. "Ah oui ! Le futur n'est pas aussi simple que cela; ce n'est pas une affaire de temps, ni de lieu, ni d'espace. C'est une question de volonté. Ou tu t'affirmes ou tu es écrabouillé." 
De l'extérieur la grande civilisation leur impose un cadre de vie, une vision du monde qui désormais les arrache au passé, à la tribu sécurisante. La civilisation et ses machines tueront tout sur leur chemin, jusqu'au fou du village, gardien du sacré et du secret, jusqu'à la mule d'Agounchich renversée à l'image du cosmos qui se renverse en renversant le monde, ses valeurs.

Lire et méditer Vie et légende d'Agounchich, c'est aussi et d'abord recontextualiser la littérature maghrébine d'expression française et en son sein retrouver la dimension berbère, témoin de la civilisation d'Afrique du Nord. L'appel de Kheir-Eddine traduit l'angoisse de tous ceux qui, comme lui, ont connu et vécu dans la culture des ancêtres et qui constatent - non sans crainte - sa disparition du sol et de l'histoire des pays du Maghreb. A la fois soucieux et prévoyant, il réintroduit grâce au récit et à la légende l'histoire de sa culture et de sa langue confrontées au cycle infernal de la mort et de la vengeance. Quelle que soit la barbarie des anciens, elle ne peut égaler la sauvagerie moderne dans son extrême brutalité et dans son extrême efficacité.

Notes

${ }^{1}$ Gilles Deleuze et Félix Guattari, Kafka, pour une littérature mineure (Paris: Editions de Minuit, 1989).

${ }^{2}$ Mouloud Féraoun, La Terre et le Sang (Paris: Éditions du Seuil, 1953).

${ }^{3}$ Mouloud Mammeri, Le Sommeil du juste (Paris: Plon, 1955).

4 Malek Ouary, Le Grain dans la meule (Paris: Buchet-Chastel, 1956).

5 in L'Arche.

6 Préface au livre de Tassadit Yacine, Aït Menguellet chante... (Paris: Éditions La Découverte / Awal, 1989).

${ }^{7}$ Légende et vie d'Agounchich (Paris: Seuil, 1984).

8 Ibid.

9 Ibid. 